\begin{tabular}{|c|c|}
\hline & $\begin{array}{c}\text { International Journal of Current Research in } \\
\text { Biosciences and Plant Biology } \\
\text { BXCELLENT } \\
\text { PUBLISHERS }\end{array}$ \\
Volume $4 \bullet$ Number 5 (May-2017) $\bullet$ ISSN: 2349-8080 (Online) \\
\hline Journal homepage: www.ijcrbp.com
\end{tabular}

\title{
Preliminary Phytochemical Analysis of Solanum nigrum L. Variant Black and Orange Fruited
}

\author{
S. Shahiladevi ${ }^{1}$ and M. Jegadeesan ${ }^{2}$ \\ ${ }^{1}$ Research Scholar, Department of Environmental and Herbal Sciences, Tamil University, Thanjavur - 613 005, Tamil Nadu, India \\ ${ }^{2}$ Professor \&Head, Department of Environmental and Herbal Sciences, Tamil University, Thanjavur - 613 005, Tamil Nadu, India
}

*Corresponding author.

\begin{tabular}{|c|c|}
\hline Abstract & Article Info \\
\hline \multirow{6}{*}{$\begin{array}{l}\text { The medicinal plant Solanum nigrum L., popularly known as black nightshade belongs to } \\
\text { the family Solanaceae was selected for preliminary phytochemical screening of secondary } \\
\text { metabolites. Phytochemical constituents like alkaloids, flavonoids, carbohydrates and } \\
\text { phytosterols were analyzed. The alkaloids in black fruited and orange fruited variants of } \\
\text { Solanum nigrum was found to } 48.61 \pm 0.83 \mathrm{mg} / \mathrm{g} 35.65 \pm 0.95 \mathrm{mg} / \mathrm{g} \text { respectively. The } \\
\text { present study suggest that Solanum nigrum variants might be a source of large amount of } \\
\text { alkaloids. The results tend to confirm the popular use of the plant. }\end{array}$} & $\begin{array}{l}\text { Accepted: } 20 \text { April } 2017 \\
\text { Available Online: } 06 \text { May } 2017\end{array}$ \\
\hline & Keywords \\
\hline & Alkaloids \\
\hline & Medicinal plant \\
\hline & Phytochemicals \\
\hline & Solanum nigrum L. \\
\hline
\end{tabular}

\section{Introduction}

The medicinal plants occupy a significant place in modern medicine as raw materials for some important drugs, although synthetic drugs and antibiotics brought about an evolution in controlling different diseases. But these synthetic drugs are out of reach for millions of people. Those who live in remote places depend on traditional healers, whom they know and trust. The judicious of medicinal herbs can even cure deadly diseases that have long defined synthetic drugs (Bhattacharjee, 2001). There are many plant herbs having different medicinal value used against various diseases since early time. Among them Solanum nigrum L. (Solanaceae) popularly known as black nightshade is one of the plants having great importance in Ayurvedic medication. The member of this family knows for the presence of natural products of medicinal significance mainly steroidal lactones, glycosides, alkaloids and flavonoids. The plant has been extensively used in traditional medicine in India and other parts of world to cure liver disorders, chronic skin ailments, inflammatory conditions, fevers, diarrhoea, ulcer etc., (Kritikar and Basu, 1935).

In the literature no work has been carried out in Solanum nigrum L. variants of black and orange fruited plants comparatively. Therefore the present study was aimed at evaluate preliminary phytochemical screening of variants of Solanum nigrum. 


\section{Materials and methods}

\section{Collection of plant sample}

The whole plants of Solanum nigrum L. variants black fruited and orange fruited were collected from Thirumalairayan Pattinam 609 606, Karaikal Region, Pondicherry, Union Territory of South India, during March - April 2011. Both plant samples were collected during same season and same time (evening).

\section{Plant identification}

The identity of the plant specimens were confirmed by using the Floras (Gamble, 1957; Matthew, 1983; Nair and Henry, 1983) and other treatises (Anonymous, 1992; Chatterjee and Pakrashi, 1994; Kirtikar and Basu, 1935). The botanical identity was also authenticated by Dr.M.Jegadeesan, Professor and Head, Department of Environmental and Herbal Sciences, Tamil University, Thanjavur, Tamil Nadu, India. Identity of the plant was confirmed with the help of type specimens available in the Herbarium of Botanical Survey of India, Southern Circle, TNAU Campus, Coimbatore, Tamil Nadu. The Herbarium specimens were prepared following the method of Jain and Rao (1976). The herbarium number in BSI is "BSI/SRC/5/23/2012-13/Tech.1480". The herbarium specimen was deposited at Tamil University Herbarium (TUH-300).

Preparation of powder (Harborne, 1973)

The shade dried entire plant powders of two plants were mechanically ground to coarse powder and passed through a 80 mesh sieve and used for further microscopical, physicochemical, phytochemical and fluorescence analysis.

Fluorescence analysis (Kokoshi et al., 1958)

Fluorescence analysis of the plants powders were observed under day light and ultraviolet (UV) light (254 $\mathrm{nm})$. Behaviours of powdered plant materials with different chemical reagents are identified.

Physicochemical studies (Anonymous, 1996)

\section{Determination of moisture content (Loss on drying)}

Two grams of the powdered samples were taken in a tared weighing bottle and weighed accurately. Dried at $105^{\circ} \mathrm{C}$ for $5 \mathrm{hrs}$ and allowed to cool in a desiccator and weighed. The drying was continued at $150^{\circ} \mathrm{C}$ and weighed at $1 \mathrm{hr}$ intervals. When the weight of the sample became constant, the loss in weight and the percentage of loss on drying were calculated.

\section{Determination of total ash value}

Two grams of powdered samples were taken in a tared silica dishes previously ignited and weighed; the ground powders were scattered in a fine even layer at the bottom of the dish and gradually by increasing heat (electrical furnace) not exceeding dull red by heating until free from carbon, cooled and weighed. As a carbon free form was not obtained, the charred mass was digested with hot water and the residue was collected in an ashless filter paper. The residue with the filter paper was incinerated and filtrate was added, evaporated to dryness and ignited at a low temperature. The percentage of ash with reference to the air dried powder was calculated.

\section{Acid insoluble ash value}

Total ash obtained was heated with addition of $25 \mathrm{ml}$ of diluted $\mathrm{HCl}$ for 10 minutes. It was filtered in an ashless filter paper (Whatman No.41) and the residue was ignited in the furnace to get a constant weight.

\section{Sulphated ash value}

The ash of the powders was moistened with $1 \mathrm{ml}$ of $\mathrm{H}_{2} \mathrm{SO}_{4}$ and ignited to $800 \pm 25^{\circ} \mathrm{C}$ until reaching a constant weight.

\section{Phytochemical studies}

Solubility percentage (Anonymous, 1985)

\section{In alcohol}

Five grams of the air-dried powders were macerated with $100 \mathrm{ml}$ of alcohol of the specified strength and kept in a closed flask for $24 \mathrm{hrs}$ and frequently shaken for 6 hrs and allowed to stand for $18 \mathrm{hrs}$. Then filtered rapidly with precautions against the loss of alcohol, $25 \mathrm{ml}$ of the filtrate was evaporated to dryness in a tarred flatbottomed shallow dish, dried at $105^{\circ} \mathrm{C}$ and weighed. The percentage of alcohol-soluble extractive with reference to the air dried samples was calculated. 


\section{In water}

The above said procedure was followed but water was used for extraction instead of alcohol. The extract was weighed and its percentage was calculated in terms of the air-dried weight of the plant material. The colour and consistency of the extracts were also noted.

\section{Preparation of extracts (Anonymous, 1996)}

The plant powders of two variants of Solanum nigrum were extracted successively using Soxhlet apparatus with petroleum ether $\left(60-80^{\circ} \mathrm{C}\right)$, hexane $\left(63-70^{\circ} \mathrm{C}\right)$ chloroform $\left(60^{\circ} \mathrm{C}\right)$ and alcohol $\left(78^{\circ} \mathrm{C}\right)$. Each time before extracting with next solvent, powdered material were dried in an air-oven below $50^{\circ} \mathrm{C}$. The extracts were dried over anhydrous sodium sulfate, stored in sealed vials in refrigerator $\left(5-8^{\circ} \mathrm{C}\right)$ until analysis.

Finally, marc was macerated with chloroform water for 24 hrs to obtain the aqueous extract. The extract was concentrated by distilling off the solvent and then evaporating to dryness on a water bath.

\section{Organoleptic characters}

Characters such as colour, odour, taste and texture of the two plant extracts were observed.

\section{Qualitative phytochemical studies}

Qualitative phytochemical analysis was carried out according to Kokate et al. (1995). Carbohydrates, alkaloids, fixed oils and fats, saponins, tannins, phenols and terpenes were qualitatively analysed.

\section{Alkaloids}

The extracts were dissolved in dilute $\mathrm{H}_{2} \mathrm{So}_{4}$ and filtrate was treated with Dragendorff's, Hager's, Mayer's and Wagner's reagent separately. Appearance of orange brown, yellow cream, pink and reddish brown precipitates in response to the above reagents respectively indicates the presence of alkaloids.

\section{Carbohydrates}

The extracts were treated with Benedict's and Fehling's reagents under suitable conditions. Appearance of brick red colour in response to the above reagents indicates the presence of carbohydrates.

\section{Fixed oils and fats}

A drop of concentrated extract was pressed in between two filter papers and kept undisturbed. The oil stains on the paper indicates the presence of oils and fats.

\section{Saponins}

About $1 \mathrm{ml}$ of the alcoholic and aqueous extracts was dissolved separately in $20 \mathrm{ml}$ of water and shaken in a graduated cylinder for 15 minutes. Formation of $1 \mathrm{~cm}$ layer of foam indicates the presence of saponins.

\section{Tannins and phenols}

Small quantity of alcoholic and aqueous extracts were dissolved in water and to that $\mathrm{FeCl}_{3}(5 \%)$ or gelatine solution $(1 \%)$ or lead acetate solution (10\%) was added. Appearance of blue colour with $\mathrm{FeCl}_{3}$ (or) precipitation with other reagents indicates the presence of tannins and phenols.

\section{Gums and mucilage}

Add about $10 \mathrm{ml}$ of aqueous extract slowly to $25 \mathrm{ml}$ of absolute alcohol with constant stirring. Precipitation indicates the presence of gums and mucilages.

\section{Quantitative phytochemical studies}

Estimation of total alkaloids (Ferguson, 1956)

The plant powder weighing $100 \mathrm{~g}$ was taken separately and soaked in alcohol for $24 \mathrm{hrs}$. Then filtered, the filtrant was extracted with $0.1 \mathrm{~N} \mathrm{HCl}$ and partitioned with chloroform in a separating funnel.

The chloroform layer was rejected and the aqueous layer basified with ammonium hydroxide to $\mathrm{pH}$ and partitioned with chloroform in a separating funnel. The aqueous layer was rejected and the chloroform layer was evaporated, the resultant content was treated as total alkaloid.

\section{Estimation of total terpenoids}

One hundred gram of plant powder was taken separately and soaked in alcohol for $24 \mathrm{hrs}$. Then filtered, the filtrant was extracted with petroleum ether and the resultant content was treated as total terpenoid. 
Estimation of tannin-free total glycoside (Jainu et al., 2006)

Air dried $100 \mathrm{~g}$ powder was extracted with ethanol water (2:1). The aqueous ethanol extracts thus obtained contains tannins which usually interfere with biological activities. Hence, this should be removed by treating with 5\% neutral lead acetate reagent which precipitates the tannins as lead tannate. The aqueous ethanolic solution was treated with $8 \%$ neutral lead acetate solution and the precipitated lead tannate was filtered off. This process is repeated with until no more precipitated was obtained. The clear filterate now contained the excess unprecipitated lead ions in solutions which were removed by passing $\mathrm{H}_{2} \mathrm{~S}$ gas into the solution. This removes the lead ions as insoluble complex black lead sulphide. The black precipitate was filtered and this process was usually reported until no more black precipitate was formed and the solution strongly smelled of $\mathrm{H}_{2} \mathrm{~S}$. The solution, usually of syrupy consistency was concentrated over water bath maintained at $55^{\circ} \mathrm{C}$. This procedure was to remove the excess of $\mathrm{H}_{2} \mathrm{~S}$.

\section{Estimation of total flavonoid (Jainu et al., 2006)}

Isolation of flavonoid from ethanol extract of any plant sample (powder) was carried out on the basis of solubility. For isolation, distilled water $(100 \mathrm{ml})$ was added to the concentrate of ethanol extract $(50 \mathrm{ml})$. After $1 \mathrm{hr}$ precipitation was observed. This precipitate was recovered by filtration. Further, the precipitate was dissolved in chloroform $(100 \mathrm{ml})$ by shaking for 15 minutes and heated gently for 5 minutes and filtered in hot state. The chloroform soluble fraction was discarded and insoluble fraction, left on filter paper was dissolved in ethyl acetate, crystallized with methanol, thereafter the residue obtained. For characterization positive result for Shinoda test which is characteristic of flavonoids.

\section{Results}

Table 1 shows the results of organoleptic characteristics of both powders of Solanum nigrum variants (Black and Orange fruited).The shade dried powder of black fruited are dark green in colour and orange fruited are pale green in colour. There is no difference in odour and taste among the powders.

Powder of Solanum nigrum (Black fruited) as such is dark green in colour. It did not show any colour difference in both visible and UV light. Powder of Solanum nigrum (Orange fruited) as such is pale green in colour. It shows colour difference in both visible and UV light. It was pale green in visible light. In UV light it was green in colour.

Fluorescent behaviour of powder of black fruited Solanum nigrum is given in Table 2 . When the powders were treated with various chemical reagents like $1 \mathrm{~N} \mathrm{NaOH}$ in water and ethanol, the powders did not show any colour change in visible and $\mathrm{UV}$ light. $1 \mathrm{~N} \mathrm{HCl}$ shows the brown colour in visible light, it was fluorescent green colour in UV light. The same result was noted in $50 \% \mathrm{HCl}$ also. The powder with $50 \% \mathrm{H}_{2} \mathrm{So}_{4}$ shows greenish brown colour in visible light and fluorescent green in UV light. The results of fluorescent behaviour of powder of Solanum nigrum L. variant Orange fruited are presented in Table 3. The powder as such in visible light is pale green in colour where as in UV light it is green colour. Powder with different chemical reagents shows remarkable colour changes in visible as well as UV light in all tested reagents.

Table 1. Organoleptic characteristics of whole plant powders of Solanum nigrum L. variants.

\begin{tabular}{llll}
\hline \multirow{2}{*}{ Sl. No. } & Characters & Powders & Orange fruited \\
\cline { 3 - 4 } & & Black fruited & Pale green \\
\hline 1. & Colour & Dark green & Characteristic and agreeable odour \\
2. & Odour & Characteristic and agreeable odour & Bitter \\
\hline
\end{tabular}

Table 2. Fluorescent behaviour of Powder of Solanum nigrum L. variant black fruited to different chemical reagents.

\begin{tabular}{llll}
\hline \multirow{2}{*}{ S. No. } & Reagent used & Powder & UV light \\
\cline { 3 - 4 } & & Visible light & Dark green \\
\hline 1. & Powder as such & Dark green & Fluorescent green \\
2. & Powder $+1 \mathrm{~N} \mathrm{NaOH}$ in water & Fluorescent green & Fluorescent green \\
3. & Powder $+1 \mathrm{~N} \mathrm{NaOH}$ in Ethanol & Fluorescent green & Fluorescent green \\
4. & Powder $+1 \mathrm{~N} \mathrm{HCl}$ & Brown & Fluorescent green \\
5. & Powder $+50 \% \mathrm{HCl}$ & Brown & Fluorescent green \\
6. & Powder $+50 \% \mathrm{H}_{2} \mathrm{SO}_{4}$ & Greenish Brown & \\
\hline
\end{tabular}


Table 3. Fluorescent behaviour of Powder of Solanum nigrum L. variant orange fruited to different chemical reagents.

\begin{tabular}{|c|c|c|c|}
\hline \multirow{2}{*}{ S. No. } & \multirow{2}{*}{ Reagent used } & \multicolumn{2}{|l|}{ Powder } \\
\hline & & Visible light & UV light \\
\hline 1. & Powder as such & Pale green & Green \\
\hline 2. & Powder $+1 \mathrm{~N} \mathrm{NaOH}$ in water & Dark Green & Yellowish Green \\
\hline 3. & Powder $+1 \mathrm{~N} \mathrm{NaOH}$ in ethanol & Fluorescent green & Fluorescent Yellowish green \\
\hline 4. & Powder + $1 \mathrm{~N} \mathrm{HCl}$ & Brown & Fluorescent green \\
\hline 5. & Powder $+50 \% \mathrm{HCl}$ & Greenish Brown & Fluorescent green \\
\hline
\end{tabular}

Table 4 shows the results of behaviour of powders of Solanum nigrum L. variant black fruited with various chemical reagents. The black fruited powders are dark green colour as such without treatment of any chemicals. There was no colour change noted when the powder was treated with conc. $\mathrm{HCl}$ and potassium hydroxide in alcohol (5\%). The remaining chemical reagents show remarkable colour changes.

Behaviours of powder Solanum nigrum L. variant Orange fruited with various chemical reagents are shown in Table 5. The powder as such is pale green in colour. The same colour was retained when the powder was treated with $\mathrm{KOH}$ in water $(5 \%)$; whereas, the powders are green in colour when treated with ammonia solution, potassium hydroxide in alcohol and sodium nitro prusside solution. The powder with acetic acid shows blackish green, whereas in ammonium oxalate solution and ferric chloride solution show yellowish green in colour and the other chemical reagents shows the noted colours change. Whole plant powders of both variants showed mostly similar characteristic features when treated with various chemical reagents.

Table 4. Behaviour of Powder of Solanum nigrum L. variant black fruited to various chemical reagents.

\begin{tabular}{lll}
\hline S. No. & Powder + Reagent used & Colour of the powder \\
\hline 1. & Powder as such & Dark Green \\
2. & Powder + Acetic acid & Greenish Black \\
3. & Powder + Ammonium oxalate solution & Green \\
4. & Powder + Ammonia solution & Yellowish Green \\
5. & Powder + Ferric chloride solution $(5 \%)$ & Pale Green \\
6. & Powder + Conc. Hydrochloric acid & Dark Green \\
7. & Powder + Iodine solution & Brownish Green \\
8. & Powder + Potassium Hydroxide in alcohol (5\%) & Dark Green \\
9. & Powder + Potassium Hydroxide in water $(5 \%)$ & Fluorescent Yellowish Green \\
10. & Powder + Conc. Nitric acid $\left(\mathrm{HNO}_{3}\right)$ & Brick Red \\
11. & Powder + Picric acid & Fluorescent Green \\
12. & Powder + Sodium Nitroprusside solution & Pale Green \\
13. & Powder + Conc. Sulphuric acid $\left(\mathrm{H}_{2} \mathrm{SO}_{4}\right)$ & Brownish Green \\
\hline
\end{tabular}

Table 5. Behaviour of Solanum nigrum L. variant orange fruited to various chemical reagents.

\begin{tabular}{lll}
\hline S. No. & Powder + Reagent used & Colour of the powder \\
\hline 1. & Powder as such & Pale Green \\
2. & Powder + Acetic acid & Blackish Green \\
3. & Powder + Ammonium oxalate solution & Yellowish Green \\
4. & Powder + Ammonia solution & Dark Green \\
5. & Powder + Ferric chloride solution $\left(\mathrm{FeCl}_{3}\right)(5 \%)$ & Yellowish Green \\
6. & Powder + Conc. Hydrochloric acid $(\mathrm{HCl})$ & Dark Black Green \\
7. & Powder + Iodine solution & Brownish Orange \\
8. & Powder + Potassium Hydroxide $(\mathrm{KOH})$ in alcohol $(5 \%)$ & Dark Green \\
9. & Powder + Potassium Hydroxide $(\mathrm{KOH})$ in water $\left(\mathrm{H}_{2} \mathrm{O}\right)(5 \%)$ & Pale Green \\
10. & Powder + Conc. Nitric acid $\left(\mathrm{HNO}_{3}\right)$ & Brick Red \\
11. & Powder + Picric acid & Fluorescent Greenish Yellow \\
12. & Powder + Sodium Nitro prusside $\mathrm{Solution}_{2}$ & Dark Green \\
13. & Powder + Conc. Sulphuric acid $\left(\mathrm{H}_{2} \mathrm{SO}_{4}\right)$ & Brownish Green \\
\hline
\end{tabular}




\section{Physicochemical studies}

Table 6 shows the physico-chemical and extractive values of Solanum nigrum. The values of all the parameters showed distinct differences in both the variants. Total ash (16.9221), acid insoluble ash value (3.3165), sulphated ash value (17.4848) and loss on drying (6.0781) are higher in variant orange fruited. Similarly, alcohol and water solubility percentage is higher in variant black fruited when compared to variant orange fruited. Extractive values of most of the extracts of variant black fruited is higher than that of variant orange fruited. In black fruited the percentage of extractability was maximum in water $(26.0 \%)$ followed by ethanol $(10.5 \%)$, petroleum ether $(1.44 \%)$ and chloroform $(1.38 \%)$ and hexane $(0.16 \%)$. Minimum extractive value was recorded in hexane $(0.16 \%)$. In orange fruited the maximum extractive value was recorded in water $(18.92 \%)$, ethanol $(9.55 \%)$, petroleum ether (1.32\%), chloroform (1.19\%) and hexane (0.24\%). While values of loss on drying, total ash value, acid insoluble ash and sulphated ash are higher in orange fruited variant, solubility percentage and extractive value in all the solvents was higher in black fruited variants.

Table 7 shows organoleptic charters of successive solvents extracts of Solanum nigrum variants. Dark green colour was observed in petroleum ether solvent in both the variants; whereas, green colour was observed in chloroform and dark brown colour in water. Other solvents such as hexane and ehthanol showed remarkable colour changes. In all successive solvents the odour remains same. As far as the taste in concern, chloroform tastes pungent in black fruited variant of Solanum nigurm, whereas slightly bitter in orange fruited variant. The rest are more or less identical in taste.

Table 6. Physicochemical and extractive values of Solanum nigrum L. variants.

\begin{tabular}{|c|c|c|c|}
\hline \multirow{2}{*}{ S.No. } & \multirow{2}{*}{ Characters } & \multicolumn{2}{|l|}{ Values in \% } \\
\hline & & Black fruited & Orange fruited \\
\hline 1. & Loss on drying at $105^{\circ} \mathrm{C}$ & 3.5600 & 6.0781 \\
\hline 2. & Total ash value & 14.1146 & 16.9221 \\
\hline 3. & Acid insoluble ash value & 1.7124 & 3.3165 \\
\hline 4. & Sulphated ash value & 15.2612 & 17.4848 \\
\hline \multirow[t]{3}{*}{5.} & Solubility percentage & & \\
\hline & a) Alcohol & 17.9634 & 12.6564 \\
\hline & b) Water & 23.3861 & 19.6379 \\
\hline \multirow[t]{6}{*}{6.} & Extractive values in & & \\
\hline & a) Petroleum ether & 1.44 & 1.32 \\
\hline & b) Hexane & 0.16 & 0.24 \\
\hline & c) Chloroform & 1.38 & 1.19 \\
\hline & d) Ethanol & 10.5 & 9.55 \\
\hline & e) Water & 26.0 & 18.92 \\
\hline
\end{tabular}

Table 7. Organoleptic characters of successive solvent extracts of Solanum nigrum variants.

\begin{tabular}{|c|c|c|c|c|c|c|c|}
\hline \multirow{2}{*}{$\begin{array}{l}\text { S. } \\
\text { No. }\end{array}$} & \multirow{2}{*}{ Extracts } & \multicolumn{3}{|l|}{ Black fruit } & \multicolumn{3}{|l|}{ Orange fruit } \\
\hline & & Colour & Odour & Taste & Colour & Odour & Taste \\
\hline 1. & Petroleum ether & Dark Green & $\begin{array}{l}\text { Characteristic } \\
\text { Odour }\end{array}$ & Bitter & Dark Green & $\begin{array}{l}\text { Characteristic } \\
\text { Odour }\end{array}$ & Bitter \\
\hline 2. & Hexane & Dark Green & $\begin{array}{l}\text { Characteristic } \\
\text { Odour }\end{array}$ & $\begin{array}{l}\text { Slightly } \\
\text { Bitter }\end{array}$ & Pale Green & $\begin{array}{l}\text { Characteristic } \\
\text { Odour }\end{array}$ & Bitter \\
\hline 3. & Chloroform & Green & $\begin{array}{l}\text { Characteristic } \\
\text { Odour }\end{array}$ & Pungent & Green & $\begin{array}{l}\text { Characteristic } \\
\text { Odour }\end{array}$ & $\begin{array}{l}\text { Slightly } \\
\text { Bitter }\end{array}$ \\
\hline 4. & Ethanol & Brown & Sharp Odour & Bitter & Dark Brown & Sharp Odour & $\begin{array}{l}\text { Strong } \\
\text { Bitter }\end{array}$ \\
\hline 5. & Water & Dark Brown & Sharp Odour & $\begin{array}{l}\text { Strong } \\
\text { Bitter }\end{array}$ & Dark Brown & Sharp Odour & $\begin{array}{l}\text { Strong } \\
\text { Bitter }\end{array}$ \\
\hline
\end{tabular}




\section{Qualitative phytochemical studies}

Presence of carbohydrate, alkaloid, fixed oils and fats, saponins, tannins and phenols, gums and mucilage and phytosterols were screened qualitatively in the successive extracts of Solanum nigrum variants. The results are summarized in Tables 8 and 9. Presence of carbohydrates was noted only in ethanol extract of variant black fruited and was noted only in water extracts in variant orange fruited. All the extracts except petroleum ether showed presence of alkaloid in both variants. The ethanol and water extracts showed positive result for saponins. The water extracts of both variants showed positive results for gums and mucilage. Tannins and phenols are noted only in ethanol and water extract of variant black fruited but in variant orange fruited, only the water extract showed the positive results.

\section{Quantitative phytochemical studies}

Total alkaloids, flavonoids, terpenoids and glycosides were estimated. Obtained results were presented in the Table 10. The variant black fruited Solanum nigrum showed higher amount of all the above phytoconstituents than that of orange fruited variant. The alkaloids content in both the variants were found to be higher than that of rest of the phytochemicals quantified. All the black fruited extracts showed terepenes positive except in water whereas in all the orange fruited extracts showed positive except in ethanol and water. Both the variants showed positive for fixed oils and fats in petroleum ether and hexane.

Table 8. Qualitative Phytochemical screening of Solanum nigrum L. variant black fruited.

\begin{tabular}{|c|c|c|c|c|c|c|c|}
\hline $\begin{array}{l}\text { S. } \\
\text { No. }\end{array}$ & Test for & Test applied / Reagent used & PetE & Hex & CHI & Eth & Wat \\
\hline \multirow[t]{2}{*}{1.} & Carbohydrate & a) Fehling's & - & - & - & + & - \\
\hline & & b) Benedict's & - & - & - & - & + \\
\hline \multirow[t]{4}{*}{2.} & Alkaloids & a) Dragendorff's & - & + & + & + & + \\
\hline & & b) Mayer's & - & + & + & + & + \\
\hline & & c) Wagner's & - & + & + & + & + \\
\hline & & d) Hagers & - & + & + & + & + \\
\hline 3. & Fixed oils and fats & Spot test & + & + & - & - & - \\
\hline 4. & Saponins & Foam test & - & - & - & + & + \\
\hline \multirow[t]{3}{*}{5.} & Tannins and phenols & a) $10 \%$ lead Acetate solution & - & - & - & + & + \\
\hline & & b) Ferric chloride solution & - & - & - & - & - \\
\hline & & c) $1 \%$ Gelatine containing $10 \%$ sodium chloride & - & - & - & - & - \\
\hline 6. & Gums and mucilage & Alcoholic precipitation & - & - & - & - & + \\
\hline 7. & Sterols/ Phytosterol/ Terpenes & Lieberman Burchard & + & + & + & + & - \\
\hline
\end{tabular}

(+) - present; (-) - completely absent; PetE-Petroleum ether; Hex-Hexane; Chl-Chloroform; Eth-Ethanol; Wat-Water.

Table 9. Qualitative Phytochemical screening of Solanum nigrum L. variant orange fruited extracts.

\begin{tabular}{|c|c|c|c|c|c|c|c|}
\hline $\begin{array}{l}\text { S. } \\
\text { No. }\end{array}$ & Test for & Test applied / Reagent used & PetE & Hex & CHI & Eth & Wat \\
\hline \multirow[t]{2}{*}{1.} & Carbohydrate & a) Fehling's & - & - & - & + & - \\
\hline & & b) Benedict's & - & - & - & + & - \\
\hline \multirow[t]{4}{*}{2.} & Alkaloids & a) Dragendorff's & - & + & + & + & + \\
\hline & & b) Mayer's & - & + & + & + & + \\
\hline & & c) Wagner's & - & + & + & + & + \\
\hline & & d) Hagers & - & + & + & + & + \\
\hline 3. & Fixed oils and fats & Spot test & + & + & - & - & - \\
\hline 4. & Saponins & Foam test & - & - & - & + & + \\
\hline \multirow[t]{3}{*}{5.} & Tannins and phenols & a) $10 \%$ lead Acetate solution & - & - & - & + & + \\
\hline & & b) Ferric chloride solution & - & - & - & - & - \\
\hline & & c) $1 \%$ Gelatine containing $10 \%$ sodium chloride & - & - & - & - & - \\
\hline 6. & Gums and mucilage & Alcoholic precipitation & - & - & - & - & + \\
\hline 7. & Sterols/ Phytosterol/ Terpenes & Lieberman Burchard & + & + & + & - & - \\
\hline
\end{tabular}

(+) - present; (-) - completely absent; PetE-Petroleum ether; Hex-Hexane; Chl-Chloroform; Eth-Ethanol; Wat-Water. 
Table 10. Quantitative phytochemical analysis of Solanum nigrum L. variants.

\begin{tabular}{llll}
\hline \multirow{2}{*}{ S. No. } & \multirow{2}{*}{ Name of the constituents } & Values in $\mathbf{~ m g} / \mathbf{g}$ & \\
\cline { 3 - 4 } & Alkaloid & $48.61 \pm 0.83$ & Orange fruited \\
\hline 2 & Flavonoids & $23.51 \pm 0.88$ & $35.65 \pm 0.95$ \\
3 & Terpenoids & $26.76 \pm 0.73$ & $13.30 \pm 0.19$ \\
4 & Glycosides & $21.02 \pm 0.83$ & $11.16 \pm 0.73$ \\
\hline
\end{tabular}

\section{Discussion}

Phytochemical is a natural bioactive compound found in plants that work with nutrients and fibers to act as a defense system against disease or more accurately, to protect against disease. Some of the most important bioactive phytochemical constituents are alkaloids, essential oils, flavonoids, tannins, terpenoids, saponins, phenolic compounds and many more (Edeoga et al., 2005).

Organoleptic investigation of whole plant powders of Solanum nigrum variants exhibited characteristic agreeable odour and bitter taste (Table 1). The fresh aerial parts of the plant are green colour. The successive solvent extracts of Solanum nigrum showed dark green to dark brown with characteristic odour. Organoleptic profile is one of the many diagnostic parameters in the proper identification of raw materials (Parvathy and Gopalakrishnan, 1991; Shanmugavadivu and Subramanian, 2009).

Fluorescence analysis of the present study revealed that the powder of Solanum nigrum black fruited as such showed fluorescent behaviour (Tables 2 and 3). On treating with various reagents, it has shown characteristic variations (Tables 4 and 5). Analytical tests based on fluorescence in day light and UV light can be used to check identity of powdered drugs (Kokoshi et al., 1958). Fluorescence profiles denote different phytochemical components that are useful in the assessment of active constituents of a drug, responsible for their pharmacological action that is useful for the preparation of genuine Ayurvedic drugs. Similar fluorescence profiling had been undertaken by Chase and Pratt (1949), Kokoshi et al. (1958), Chitra and Thoppil (2002).

Reports of the present investigation revealed that the plant samples contain $3.5600 \%$ moisture content in variant black fruited and $6.078 \%$ in variant orange fruited (Table 6) (loss on drying). It determines the water drying off from the drug and is used for substance appearing to contain water as the major constituent. The ash content found in the present study sample was presented in Table
6 on dry weight basis. To determine ash content, the plant material is burnt and the residual ash is measured as total and acid-insoluble ash.

In the present study, extractive values of plant powders of Solanum nigrum variants revealed that the percentage of extractability was maximum in water $(26.0 \%)$ followed by ethanol (10.5\%), petroleum ether $(1.44 \%)$ and chloroform $(1.38 \%)$ and hexane $(0.16 \%)$. Minimum extractive value was recorded in hexane $(0.16 \%)$. The maximum extractive value was recorded in water $(18.92 \%)$, ethanol $(9.55 \%)$, petroleum ether $(1.32 \%)$, chloroform $(1.19 \%)$ and hexane $(0.24 \%)$ in the black and orange fruited variants respectively. Different extractive value and chemical group tests of different solvent extracts show a path for isolation of different active constituents present in the extracts. Extractive value profiles help in the detection of adulterants during the process of authentication of crude and raw drug materials. Earlier works had revealed extractive value profiles in several medicinal plants (Sharma and Habib, 1995; Khatoon et al., 2006).

Qualitative screening in the present study revealed the presence of carbohydrate, alkaloid, fixed oils and fats, saponins, tannins and phenols, gums and mucilage and phytosterols. Preliminary qualitative test according to Mallikharjunah et al. (2007) is useful in the detection of bioactive principles and subsequently may lead to drug discovery and development (Tables 8 and 9). Similar results were also reported by Djaafar and Ridha (2014) in Solanum nigrum the Algerian Desert. The data obtained in the present work confirm the relatedness of the investigated Solanum nigrum species, as well as reveal their potentials in the drug industry. Similar results were also reported by Elias et al. (2013) who under took pharmacognostical, phytochemical and anthelmentics activity on leaves of Solanum nigrum and discovered the presence of tannins, alkaloids and flavonoids in all the samples.

The present study revealed the presence of the subject secondary metabolites in the variants (Table 10) which is taxonomically useful (Parekh et al., 2005) and it also 
brings to bare the fact that the study plant is potential sources of these important phytochemicals.

\section{Conflict of interest statement}

Authors declare that they have no conflict of interest.

\section{References}

Anonymous, 1985. Pharmacopoeia of India. Govt. of India Publication, Ministry of Health, New Delhi.

Anonymous, 1992. The Wealth of India. CSIR, New Delhi. pp.56-57.

Anonymous, 1996. Pharmacopiea of India (The Indian Pharmacopiea). $3^{\text {rd }}$ Edn. Ministry of Health and Family Welfare, Govt. of India, New Delhi. pp.5354.

Bhattacharjee, S. K., 2001. Handbook of Medicinal Plants. $3^{\text {rd }}$ Edn. Pointer Publ., Jaipur (India).

Chase, C.R., Pratt, R.J., 1949. Fluorescence of powdered vegetable drugs with particular reference to development of a system of identification. J. Am. Pharmaceut. Assoc. 38(6), 324-331.

Chatterjee, A., Pakrashi, S.K., 1994. The Treatise on Indian Medicinal Plants. Publication and Information Directorate, New Delhi. pp.70-75.

Chitra, M., Thoppil, J.E., 2002. Pharmacognostical and phytochemical studies on Curcuma amada L. rhizome (Zingiberaceae). Anc. Sci. Life. 22, 25-33.

Djaafar, Z., Ridha, O.M., 2014. Phytochemical study of selected medicinal plant, Solanum nigrum, the Algerian Desert. Int. Lett. Chem. Phys. Astron. 20, 25-30.

Edeoga, H.O., Okwu, D.E., Mbaebie, B.O., 2005. Phytochemical constiuents of some Nigerian medicinal plants. Afr. J. Biotechnol. 4(7), 685-688.

Elias, A., Ravichandran, S., Karthika, T., Maharajan, T., Satyamala, P., Lingeshwari, D., 2013. Pharmacogostical, phytochemical and anthelmintic activity on leaves of Solanum nigrum Linn. .Asian J. Res. Bio.Pharmaceut. Sci. 1(1), 1-8.

Ferguson, N.M., 1956. A Text Book of Pharmacognosy. Macmillan Company. 191p.

Gamble, J.S., 1957. Flora of Presidency of Madras. Botanical Survey of India, Culcutta, India.

Harborne, J.B., 1973. Phytochemical Methods ( $1^{\text {st }}$ Edn.). Chapman and Hall, London.
Jain, S.K., Rao, R.R., 1976. A Handbook of Field and Herbarium Methods. Today and Tomorrow Publishers, New Delhi.

Jainu, M., Devi, C.S.S., 2006. Antiulcerogenic and ulcer healing effects of Solanum nigrum (L.) on experimental ulcer models: Possible mechanism for the inhibition of acid formation. J. Ethnopharmacol. 104, 156-163.

Khatoon, S., Rai, V., Rawat, A.K., Mehrotra, S., 2006. Comparative pharmacognostic studies of three Phyllanthus species. J. Ethnopharmacol. 104, 79-86.

Kritikar, K.R., Basu, B.D., 1935. Indian Medicinal Plants. Bishen Singh Mahendra Pal Singh, Dehra Dun. pp.2051-2069.

Kokoshi, C.J., Kokoshi, R.J., Sharma, F.J., 1958. Fluorescence of powdered vegetable drugs under UV radiations. Sci. J. Am. Pharm. Assoc. 48(10), 715-717.

Kokate, C.K., Khandelwal, K.R., Pawar, A.P., Gohale, S.B., 1995. Practical Pharmacognosy ( $3^{\text {rd }}$ Edn.). NiraliPrakashan, Pune. pp.137-139.

Mallikharjunah, P.B., Rajanna, L.N., Seetharam, Y.N., Sharanabasappa, G.K., 2007. Phytochemical studies of Strychnos potatorum L. f.- A medicinal plant. Eur. J. Chem. 4, 510-518.

Matthew, K.M., 1983. The Flora of Tamilnadu Carnatic. The Rapinat Herbarium, Tiruchirapalli.

Nair, N.C., Henry, A.N., 1983. Flora of Tamil Nadu, India, Series I, Vol.I. Botanical Survey of India, Southern Circle, Coimbatore, India.

Parekh, J., Jadeja, D., Chanda, S., 2005. Efficacy of aqueous and methanol extracts of some medicinal plants for potential antibacterial activity. Turk. J. Biol. 29, 203-210.

Parvathy, P., Gopalakrishnan, S., 1991. Macro and microscopical studies on the leaf and rhizome of Alpinia galanga L. Indian. J. Pharmacol. 18, 4246.

Shanmugavadivu, R., Subramanian, M.S., 2009. Study on the phytochemical constitution of Albizzia lebbeck Benth. Asian J. Bio.Sci. 4(1), 107-108.

Sharma, B.K., Habib, I., 1995. Differential bioaccumulation of $\mathrm{Mg}, \mathrm{Pb}, \mathrm{Cr}$ and $\mathrm{Zn}$ in some Rabi crops and elemental bioaccumulation, metabolite concentration in component parts of Cicer arietinum var. C-235 under irrigational impact of rubber factory effluent. J. Indian Bot. Soc. 74, 197-204.

\section{How to cite this article:}

Shahiladevi, S., Jegadeesan, M., 2017. Preliminary phytochemical analysis of Solanum nigrum L. variant black and orange fruited. Int. J. Curr. Res. Biosci. Plant Biol. 4(5), 65-73. doi: https://doi.org/10.20546/ijcrbp.2017.405.009 